\title{
Carbon acquisition of marine phytoplankton: Effect of photoperiod length
}

\author{
Björn Rost ${ }^{1}$
}

Alfred Wegener Institute for Polar and Marine Research, Am Handelshaven 12, 27515 Bremerhaven, Germany

\section{Ulf Riebesell}

Leibniz Institute for Marine Sciences, University of Kiel, Duesternbrooker Weg 20, 24105 Kiel, Germany

\section{Dieter Sültemeyer}

Fachbereich Biologie, University of Kaiserslautern, Erwin-Schroedinger-Strasse 13, 67653 Kaiserslautern, Germany

\begin{abstract}
We investigated the carbon acquisition of three marine microalgae, Skeletonema costatum, Phaeocystis globosa, and Emiliania huxleyi in response to different light regimes. Rates of photosynthetic $\mathrm{O}_{2}$ evolution and $\mathrm{CO}_{2}$ and $\mathrm{HCO}_{3}^{-}$uptake were measured by membrane inlet mass spectrometry in cells acclimated to cycles of 16:8 light: dark (LD; $\mathrm{h}: \mathrm{h})$ and 12:12 LD and were compared with those obtained under continuous light. In addition, cellular leakage was estimated for different photoperiods and ambient $\mathrm{CO}_{2}$ concentrations during growth. Maximum rates of photosynthesis more or less doubled under LD cycles compared with continuous light. In S. costatum and E. huxleyi, a remarkably higher contribution of $\mathrm{HCO}_{3}^{-}$to the overall carbon uptake was observed under LD cycles. In contrast, $P$. globosa did not change its $\mathrm{CO}_{2}: \mathrm{HCO}_{3}^{-}$uptake ratio in response to daylength. Half saturation concentrations $\left(K_{1 / 2}\right)$ for $\mathrm{O}_{2}$ evolution and inorganic carbon $(\mathrm{Ci})$ uptake were also influenced by the photoperiod. Under LD cycles $K_{1 / 2}$ values for photosynthesis in $S$. costatum and $P$. globosa were similar or higher compared with continuous light, whereas they were much lower in E. huxleyi. With the exception of $\mathrm{CO}_{2}$ uptake in E. huxleyi and P. globosa, affinities for Ci decreased under the LD cycles. Cellular leakage was highest for E. huxleyi and lowest for $S$. costatum and generally decreased with increasing $\mathrm{CO}_{2}$ concentration. Although this study confirms speciesspecific differences in the $\mathrm{CO}_{2}$-concentrating mechanisms (CCMs), the effect of daylength on $\mathrm{CO}_{2}$ and $\mathrm{HCO}_{3}^{-}$uptake has hitherto not been described. We put forward the idea that variations in light condition influence the cellular carbon demand, thereby imposing a stronger control on CCM regulation than the naturally occurring changes in $\mathrm{CO}_{2}$ supply.
\end{abstract}

Inorganic carbon acquisition has been suggested to play an important role in marine phytoplankton ecology and evolution (e.g., Badger et al. 1998; Tortell 2000; Giordano et al. 2005). Despite the relatively high concentrations of dissolved inorganic carbon in the ocean, phytoplankton cells have to invest considerable resources in carbon acquisition to allow for high rates of photosynthesis. This situation is mainly caused by the "imperfection" of their primary carboxylating enzyme, ribulose-1,5-bisphosphate carboxylase/ oxygenase (RubisCO), which is characterized by a low affinity for its substrate $\mathrm{CO}_{2}$, a slow maximum specific turnover rate, and susceptibility to a competing reaction with $\mathrm{O}_{2}$. To avoid the risk of carbon limitation, most microalgae have thus developed different mechanisms that enhance the intracellular $\mathrm{CO}_{2}$ concentration at the site of carboxylation (Badger et al. 1998). These $\mathrm{CO}_{2}$-concentrating mechanisms (CCMs) involve active uptake of $\mathrm{CO}_{2}$ or $\mathrm{HCO}_{3}^{-}$or both, as

\footnotetext{
${ }^{1}$ Corresponding author (brost@awi-bremerhaven.de).
}

\section{Acknowledgments}

We thank Steffen Burkhardt, Gabi Amoroso, Dominik Müller, and Christoph Thyssen for technical support and laboratory assistance and two anonymous reviewers for their constructive comments on the manuscript. This work was supported by the German Science Foundation (TH74412) and the German-Israeli Cooperation in Marine Sciences, which is funded by the German Federal Ministry of Education and Research. well as the enzyme carbonic anhydrase (CA), which accelerates the otherwise slow conversion rate between $\mathrm{HCO}_{3}^{-}$ and $\mathrm{CO}_{2}$. Recent data suggest the possibility that a $\mathrm{C}_{4}$-like pathway might operate, together with active $\mathrm{HCO}_{3}^{-}$uptake, in diatoms (Reinfelder et al. 2000, 2004). This involves the formation of oxalacetate and malate by phosphoenolpyrovate carboxylase, which has the advantage over RubisCO of a high affinity for its carbon source $\mathrm{HCO}_{3}^{-}$along with insensitivity to $\mathrm{O}_{2}$.

Phytoplankton species differ in efficiency and regulation of their carbon acquisition (e.g., Burkhardt et al. 2001; Rost et al. 2003; Giordano et al. 2005). Species relying on diffusive $\mathrm{CO}_{2}$ uptake or those with inefficient CCMs are $\mathrm{CO}_{2}$ sensitive in their photosynthesis, whereas species with highly efficient CCMs are rate saturated even under low ambient $\mathrm{CO}_{2}$ concentrations. The capability of regulation allows phytoplankton to adjust CCM efficiency to their actual need, thereby optimizing the allocation of resources. Understanding the factors influencing CCM efficiency could help to elucidate the role of carbon acquisition in phytoplankton ecology. As one of these factors, $\mathrm{CO}_{2}$ supply has early on been identified and subsequently used to investigate the properties of CCMs by comparing incubations at different $\mathrm{CO}_{2}$ concentrations. While most studies compare unnaturally high with ambient $\mathrm{CO}_{2}$ levels, implying distinct repression or induction of the $\mathrm{CCM}$, current findings indicate that under the natural range of $\mathrm{CO}_{2}$ concentrations, there is a fine-scale 
tuning in the degree to which the CCM is expressed (Berman-Frank et al. 1998; Burkhardt et al. 2001; Rost et al. 2003). Photon flux density (PFD) also influences CCM efficiency in microalgae. Increasing light limitation yielded a decrease in dissolved inorganic carbon affinities, which has been ascribed to the effect of energy supply on active carbon uptake (Beardall 1991; Berman-Frank et al. 1998).

The effect of daylength has been studied on different aspects of algal physiology, including photosynthesis. Nielsen (1997) investigated the influence of daylength on the photosynthesis of Emiliania huxleyi, finding a threefold higher chlorophyll $a(\mathrm{Chl} a)$-specific maximum photosynthetic rate when cells were grown under a cycle of 12:12 light: dark (LD) compared with continuous light. Moreover, some microalgae are able to keep their carbon-specific growth rate more or less constant independent of daylength (Price et al. 1998; Burkhardt et al. 1999; Rost et al. 2002), which requires that rates of carbon fixation increase with decreasing photoperiod length. When carbon-specific growth rates are normalized for the duration of the photoperiod, an almost twofold increase from continuous light to 12:12 LD for Skeletonema costatum (Burkhardt et al. 1999) and about 1.5fold increase from continuous light to 16:8 LD for E. huxleyi (Rost et al. 2002) was observed. Mortain-Bertrand et al. (1987a) reported a stimulation of photosynthesis in cycling light for S. costatum compared with continuous light. Further indication for the effect of photoperiod on carbon acquisition stems from experiments on carbon isotope fractionation $\left(\varepsilon_{\mathrm{p}}\right)$. Species such as $S$. costatum and $E$. huxleyi showed significantly lower $\varepsilon_{\mathrm{P}}$ values under LD cycles compared with continuous light (Burkhardt et al. 1999; Rost et al. 2002). On the basis of this pattern of isotope fractionation, as well as the daylength-dependent changes in the carbon fixation rate, Rost et al. (2002) postulated that daylength influences the regulation of carbon acquisition in E. huxleyi and other microalgae.

In this study, we investigated inorganic carbon acquisition of three dominant bloom-forming species, S. costatum, Phaeocystis globosa, and E. huxleyi, in response to changes in photoperiod length. We examined $\mathrm{O}_{2}$ evolution under steady-state photosynthesis and quantified $\mathrm{CO}_{2}$ and $\mathrm{HCO}_{3}^{-}$ uptake rates as well as cellular leakage $\left(\mathrm{CO}_{2}\right.$ efflux : $\mathrm{Ci}$ uptake) with the use of membrane inlet mass spectrometry.

\section{Material and methods}

Culture conditions and sampling-S. costatum, P. globosa (both strains collected in the North Sea and maintained in stock culture for several years), and a calcifying strain of E. huxleyi (B92/11) were grown at $15^{\circ} \mathrm{C}$ in $0.2-\mu \mathrm{m}$ filtered seawater (salinity 32), which was enriched according to $\mathrm{f} / 2$ medium (Guillard and Ryther 1962). Batch cultures were grown in 1-liter glass tubes with 360 parts per million by volume (ppmv) $\mathrm{CO}_{2}$ and an incident PFD of $180 \mu \mathrm{mol}$ photons $\mathrm{m}^{-2} \mathrm{~s}^{-1}$. Cells were acclimated for at least $4 \mathrm{~d}$ to LD cycles of $16: 8$ and 12:12. Cells were harvested by centrifugation 4 to $7 \mathrm{~h}$ after the beginning of the photoperiod to allow photosynthesis and CCM activity to be fully induced (Marcus et al. 1986). A subsample of the culture was used for potentiometric $\mathrm{pH}$ measurements. Cultures in which the $\mathrm{pH}$ had shifted significantly from that of a cell-free control ( $\mathrm{pH}$ drift $>0.05$ ) were excluded from further measurements.

To concentrate the cells for the measurements, $800 \mathrm{ml}$ of the culture were centrifuged at $500-1,000 \times \mathrm{g}$ at $15^{\circ} \mathrm{C}$ for $4 \mathrm{~min}$. Subsequently, cells were washed in $\mathrm{CO}_{2}$-free $\mathrm{f} / 2 \mathrm{me}$ dium buffered with 2-[4-(2-hydroxyethyl)-1-piperazinyl]ethanesulfonic acid (HEPES, $50 \mathrm{mmol} \mathrm{L}^{-1}, \mathrm{pH}$ 8.0). Samples for Chl $a$ determination were taken after the measurements by centrifuging $2 \mathrm{ml}$ of the cell suspension $(4,500 \times \mathrm{g}, 4$ min). Chl $a$ was subsequently extracted in $1 \mathrm{ml}$ of methanol $\left(1 \mathrm{~h}\right.$ in darkness, at $\left.4^{\circ} \mathrm{C}\right)$ and determined spectrophotometrically at 652 and $665 \mathrm{~nm}$. Chl $a$ concentrations in the culture ranged from 5 to $35 \mu \mathrm{g} \mathrm{L}^{-1}$ at the time of sampling. The carbonate system was determined according to Burkhardt et al. (2001).

Determination of net photosynthesis and inorganic carbon fluxes-To investigate inorganic carbon (Ci) fluxes during steady-state photosynthesis, a quadropole membrane inlet mass spectrometer (MSD 5970; Hewlett Packard) was used. Net photosynthesis was measured by monitoring the $\mathrm{O}_{2}$ concentration over consecutive $\mathrm{LD}$ intervals with increasing $\mathrm{Ci}$ concentrations. Simultaneous measurements of the $\mathrm{CO}_{2}$ concentration enabled us to determine the $\mathrm{CO}_{2}$ uptake and $\mathrm{HCO}_{3}^{-}$uptake kinetics according to equations by Badger et al. (1994). This method has been applied in several studies of cyanobacteria and freshwater microalgae (Palmqvist et al. 1994; Tchernov et al. 1997; Sültemeyer et al. 1998) and recently also of marine phytoplankton (Burkhardt et al. 2001; Rost et al. 2003). Cellular leakage was estimated from the $\mathrm{CO}_{2}$ efflux observed right after turning off the light (Badger et al. 1994). In this study, we largely followed the protocol described by Burkhardt et al. (2001). All measurements were performed in $\mathrm{f} / 2$ medium buffered with $50 \mathrm{mmol} \mathrm{L}^{-1}$ HEPES ( $\mathrm{pH} 8.0)$ at $15^{\circ} \mathrm{C}$. Dextran-bound sulfonamide (DBS), a membrane-impermeable inhibitor of external CA, was added to the cuvette to a final concentration of 100 $\mu \mathrm{mol} \mathrm{L}{ }^{-1}$. Chl $a$ concentration ranged between 1 and $3 \mu \mathrm{g}$ $\mathrm{ml}^{-1}$. Light and dark intervals during the assay lasted 6 and 7 min, respectively. The incident photon flux density was $300 \mu \mathrm{mol} \mathrm{m} \mathrm{m}^{-2} \mathrm{~s}^{-1}$. For further details on the method and calculation, we refer to Badger et al. (1994) and Burkhardt et al. (2001).

\section{Results}

Acclimation to different photoperiods leads to large responses in photosynthesis and carbon uptake, an effect that differs between species. Net photosynthesis and $\mathrm{Ci}$ uptake are shown as a function of $\mathrm{CO}_{2}$ or $\mathrm{HCO}_{3}^{-}$concentrations, or both, for $S$. costatum, $P$. globosa, and E. huxleyi acclimated to different LD cycles (Figs. 1-3), and kinetic parameters such as half-saturation concentrations $\left(K_{1 / 2}\right)$ and maximum rates $\left(V_{\max }\right)$ are summarized in Table 1.

In all investigated species, the $V_{\max }$ of photosynthetic $\mathrm{O}_{2}$ evolution were up to twofold higher under the LD cycles compared with continuous light (Figs. 1-3; Table 1). $K_{1 / 2}$ values for $\mathrm{O}_{2}$ evolution were generally highest for $E$. huxleyi and lowest for $P$. globosa, reflecting species-specific differ- 


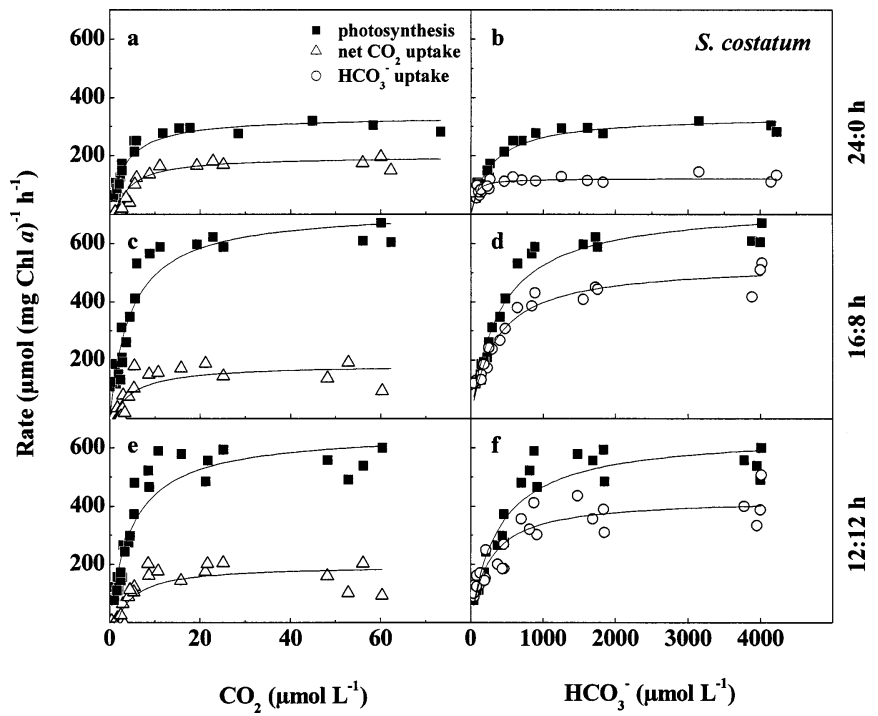

Fig. 1. S. costatum. Chl $a$-specific rates of net photosynthesis, net $\mathrm{CO}_{2}$ uptake, and $\mathrm{HCO}_{3}^{-}$uptake as a function of $\mathrm{CO}_{2}$ and $\mathrm{HCO}_{3}^{-}$concentrations in the assay medium. The cultures were grown at 360 ppmv $\mathrm{CO}_{2}$ and acclimated to LD cycles of $(\mathrm{a}, \mathrm{b}) 24$ : 0 , (c, d) $16: 8$, or $(e, f) 12: 12$ for at least $4 \mathrm{~d}$. Curves were obtained from a Michaelis-Menten fit to the combined data of several independent measurements.

ences in overall affinities for inorganic carbon. Under LD cycles $K_{1 / 2}$ values in $S$. costatum and $P$. globosa were similar or higher compared with continuous light, whereas they were much lower in E. huxleyi. In all three species, we observed simultaneous uptake of $\mathrm{CO}_{2}$ and $\mathrm{HCO}_{3}^{-}$(Figs. 1-3; Table 1). In $S$. costatum, daylength had no significant effect on $V_{\max }$ or $K_{1 / 2}$ of $\mathrm{CO}_{2}$ uptake. In P. globosa and E. huxleyi, the $V_{\max }$ increased slightly or showed no clear trend, respectively, whereas the data indicate higher affinities for $\mathrm{CO}_{2}$ under $\mathrm{LD}$ cycles in both species. The largest changes in response to daylength were observed in the $\mathrm{HCO}_{3}^{-}$uptake systems. The $V_{\max }$ for $\mathrm{HCO}_{3}^{-}$uptake were consistently higher under LD cycles in all three species. Affinities for $\mathrm{HCO}_{3}^{-}$decreased under the LD cycles in S. costatum, P. globosa, and possibly E. huxleyi. The strong effect of the photoperiod on photosynthesis can thus partly be ascribed to generally higher uptake rates of carbon along with increasing relative contribution of $\mathrm{HCO}_{3}^{-}$under LD cycles.

The efficiency of a CCM can be assessed by the ratio of $K_{\mathrm{M}}\left(\mathrm{CO}_{2}\right)$ of RubisCO and the apparent $K_{1 / 2}\left(\mathrm{CO}_{2}\right)$ of photosynthetic $\mathrm{O}_{2}$ evolution. Although $K_{\mathrm{M}}: K_{1 / 2}$ ratios were generally lower under LD cycles for $S$. costatum and $P$. globosa compared with continuous light, the ratio was higher for $E$. huxleyi (Fig. 4a). P. globosa showed ratios of up to 24 , whereas E. huxleyi reached only up to 5. With the use of the uptake kinetics obtained in our assay, we estimated the ratio of $\mathrm{CO}_{2}$ to $\mathrm{HCO}_{3}^{-}$uptake for conditions of the respective incubation (Fig. 4b). Calculation of these uptake ratios is based on the assumption that the $\mathrm{CO}_{2}$ and $\mathrm{HCO}_{3}^{-}$uptake systems are regulated independently and that $\mathrm{pH}$ differences between assay ( $\mathrm{pH} \mathrm{8.0)}$ and acclimation ( $\mathrm{pH} 8.2)$ have no significant effect. Values $>1$ indicate a preference for $\mathrm{CO}_{2}$ and values $<1$ a preference for $\mathrm{HCO}_{3}^{-}$as the substrate. In all three spe-

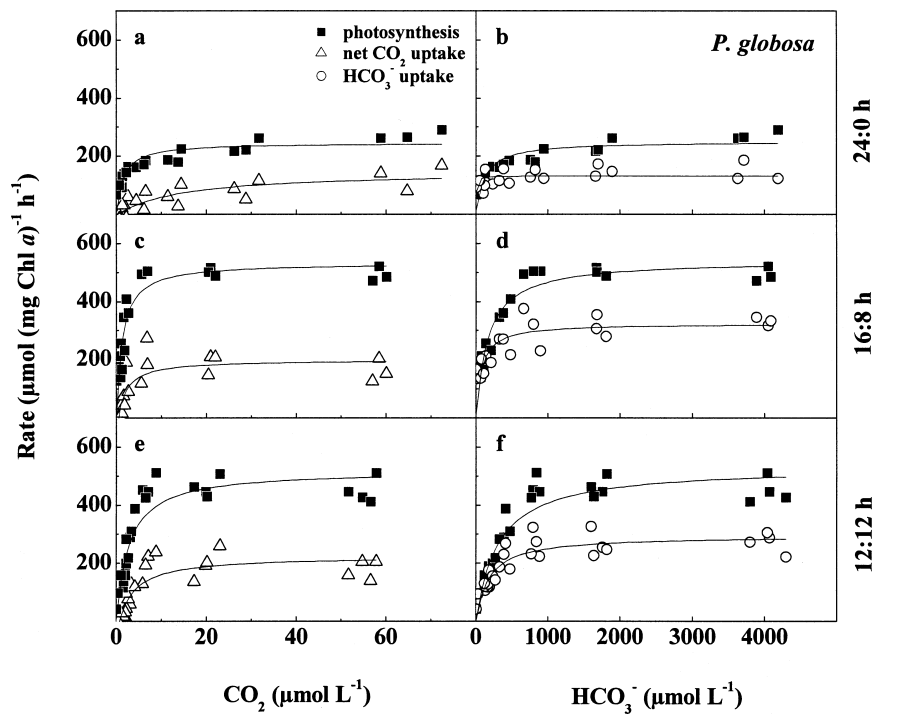

Fig. 2. P. globosa. Chl $a$-specific rates of net photosynthesis, net $\mathrm{CO}_{2}$ uptake, and $\mathrm{HCO}_{3}^{-}$uptake as a function of $\mathrm{CO}_{2}$ and $\mathrm{HCO}_{3}^{-}$concentrations in the assay medium. The cultures were grown at 360 ppmv $\mathrm{CO}_{2}$ and acclimated to $\mathrm{LD}$ cycles of $(\mathrm{a}, \mathrm{b}) 24$ : 0 , (c, d) $16: 8$, or (e, f) $12: 12$ for at least $4 \mathrm{~d}$. Curves were obtained from a Michaelis-Menten fit.

cies, the preference for $\mathrm{HCO}_{3}^{-}$was higher under $\mathrm{LD}$ cycles than under continuous light. S. costatum and E. huxleyi showed the largest variations in $\mathrm{CO}_{2}: \mathrm{HCO}_{3}^{-}$uptake ratios between treatments, whereas in $P$. globosa, changes were small.

The leakage of cells (i.e., the proportion of $\mathrm{C}_{\mathrm{i}}$ efflux compared with gross $\mathrm{C}_{\mathrm{i}}$ uptake) was estimated from the $\mathrm{CO}_{2}$ efflux observed upon darkening. For all species, leakage was

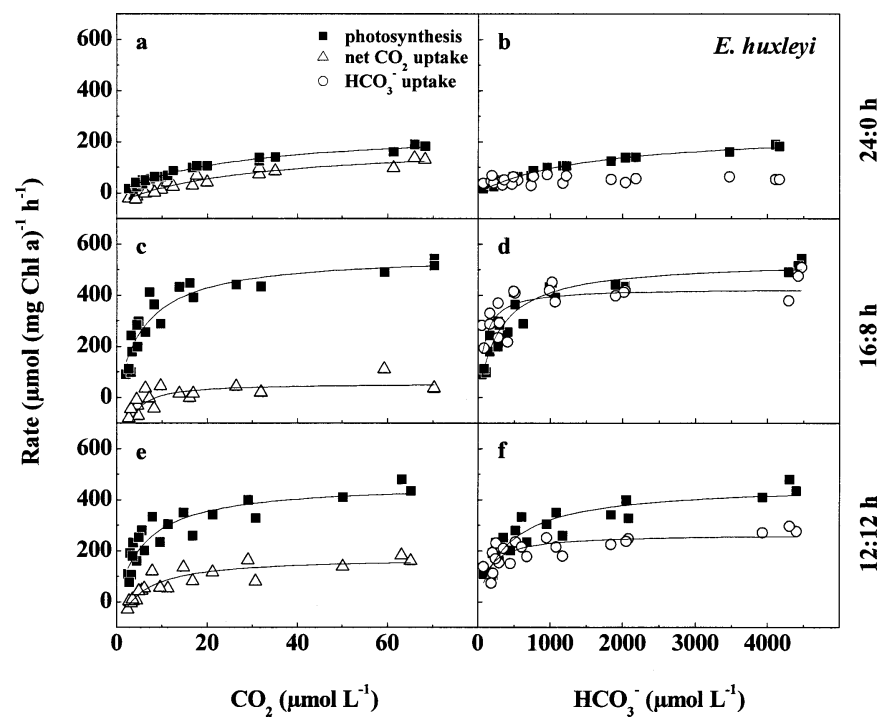

Fig. 3. E. huxleyi. Chl $a$-specific rates of net photosynthesis, net $\mathrm{CO}_{2}$ uptake, and $\mathrm{HCO}_{3}^{-}$uptake as a function of $\mathrm{CO}_{2}$ and $\mathrm{HCO}_{3}^{-}$ concentrations in the assay medium. The cultures were grown at 360 ppmv $\mathrm{CO}_{2}$ and acclimated to LD cycles of (a, b) $24: 0$, (c, d) $16: 8$, or (e, f) $12: 12$ for at least $4 \mathrm{~d}$. Curves were obtained from a Michaelis-Menten fit. 
Table 1. $K_{1 / 2}\left(\mu \mathrm{mol} \mathrm{L}{ }^{-1}\right)$ and $V_{\max }\left(\mu \mathrm{mol}[\mathrm{mg} \mathrm{Chl} a]^{-1} \mathrm{~h}^{-1}\right)$ of photosynthesis, net $\mathrm{CO}_{2}$ uptake, and $\mathrm{HCO}_{3}^{-}$uptake for $S$. costatum, P. globosa, and E. huxleyi acclimated at different LD cycles. Kinetic parameters were calculated from a Michaelis-Menten fit to the combined data of several independent measurements. Error bars denote \pm SD.

\begin{tabular}{|c|c|c|c|c|c|c|c|}
\hline \multirow[b]{2}{*}{ LD $(\mathrm{h}: \mathrm{h})$} & \multicolumn{3}{|c|}{ Photosynthesis } & \multicolumn{2}{|c|}{$\mathrm{CO}_{2}$ uptake } & \multicolumn{2}{|c|}{$\mathrm{HCO}_{3}^{-}$uptake } \\
\hline & $K_{1 / 2}\left(\mathrm{CO}_{2}\right)$ & $K_{1 / 2}\left(\mathrm{HCO}_{3}^{-}\right)$ & $V_{\max }$ & $K_{1 / 2}\left(\mathrm{CO}_{2}\right)$ & $V_{\max }$ & $K_{1 / 2}\left(\mathrm{HCO}_{3}^{-}\right)$ & $V_{\max }$ \\
\hline \multicolumn{8}{|l|}{ S. costatum } \\
\hline $24: 0$ & $2.3 \pm 0.5$ & $246 \pm 40$ & $353 \pm 16$ & $4.9 \pm 0.6$ & $198 \pm 9$ & $38 \pm 14$ & $115 \pm 6$ \\
\hline $16: 8$ & $4.6 \pm 0.8$ & $393 \pm 50$ & $731 \pm 30$ & $5.6 \pm 1.9$ & $185 \pm 23$ & $335 \pm 41$ & $531 \pm 20$ \\
\hline $12: 12$ & $4.9 \pm 0.8$ & $390 \pm 60$ & $650 \pm 31$ & $6.0 \pm 1.7$ & $197 \pm 23$ & $260 \pm 53$ & $427 \pm 24$ \\
\hline \multicolumn{8}{|l|}{ P. globosa } \\
\hline $24: 0$ & $1.5 \pm 0.4$ & $122 \pm 29$ & $251 \pm 13$ & $15.0 \pm 9.4$ & $148 \pm 33$ & $23 \pm 13$ & $133 \pm 7$ \\
\hline $16: 8$ & $1.3 \pm 0.6$ & $164 \pm 34$ & $542 \pm 26$ & $2.4 \pm 0.8$ & $199 \pm 22$ & $76 \pm 28$ & $325 \pm 22$ \\
\hline $12: 12$ & $2.8 \pm 0.5$ & $310 \pm 48$ & $524 \pm 25$ & $4.4 \pm 1.1$ & $224 \pm 21$ & $181 \pm 36$ & $295 \pm 15$ \\
\hline \multicolumn{8}{|l|}{ E. huxleyi } \\
\hline $24: 0$ & $27.3 \pm 2.4$ & $1,562 \pm 147$ & $245 \pm 13$ & $42.9 \pm 11$ & $197 \pm 32$ & - & $58 \pm 15$ \\
\hline $16: 8$ & $6.2 \pm 1.1$ & $304 \pm 45$ & $534 \pm 22$ & $17.5 \pm 5.1$ & $55 \pm 19$ & $84 \pm 31$ & $426 \pm 26$ \\
\hline $12: 12$ & $6.3 \pm 1.3$ & $431 \pm 84$ & $459 \pm 29$ & $11.4 \pm 3.1$ & $174 \pm 21$ & $157 \pm 46$ & $265 \pm 17$ \\
\hline
\end{tabular}

highest under low ambient $\mathrm{CO}_{2}$ and leveled off toward higher $\mathrm{CO}_{2}$ concentrations in the assay (Fig. 5). This $\mathrm{CO}_{2}$ dependence in leakage was then used to calculate leakage under conditions of the respective incubations (Fig. 6a,b).
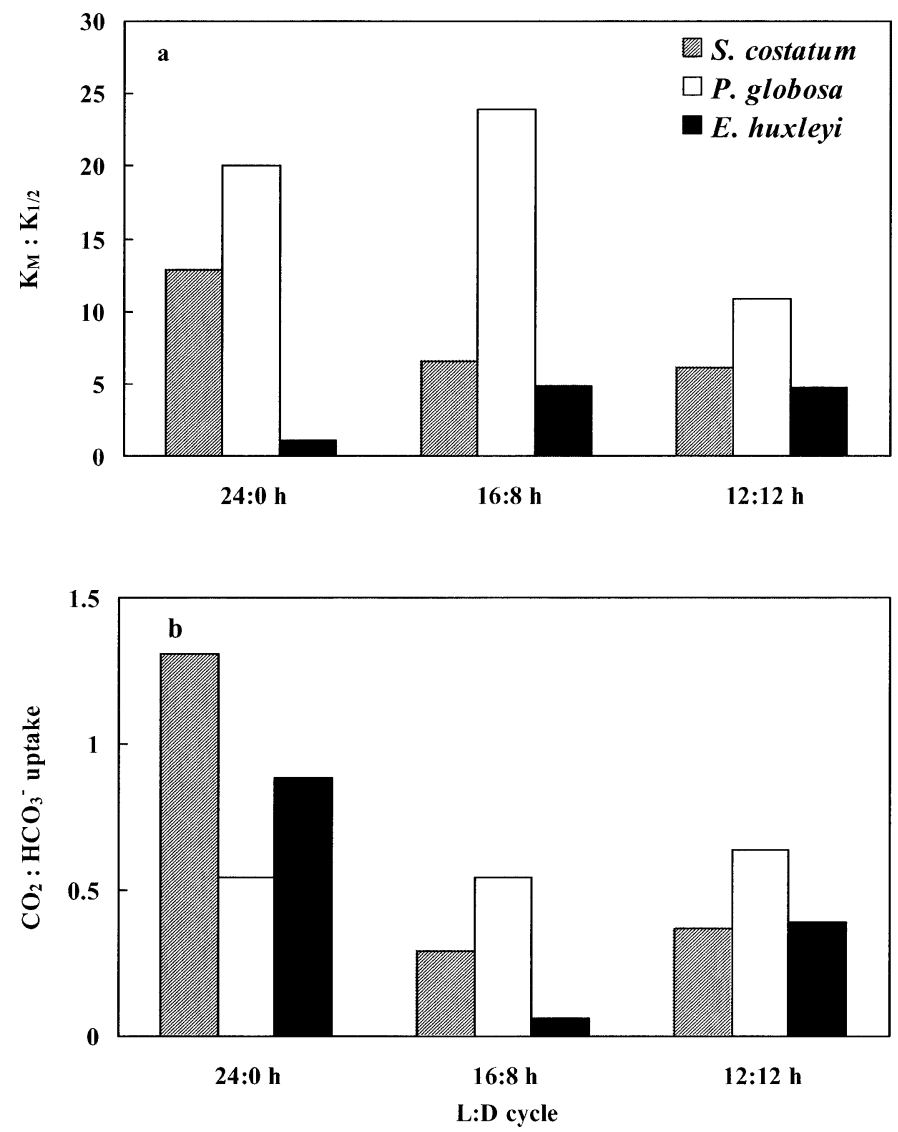

Fig. 4. (a) Ratios of $K_{\mathrm{M}}\left(\mathrm{CO}_{2}\right)_{\text {Rubisco }}: K_{1 / 2}\left(\mathrm{CO}_{2}\right)$ for $\mathrm{O}_{2}$ evolution and (b) $\mathrm{CO}_{2}: \mathrm{HCO}_{3}^{-}$uptake ratios in $S$. costatum, P. globosa, and $E$. huxleyi acclimated to different LD cycles. $K_{\mathrm{M}}\left(\mathrm{CO}_{2}\right)_{\mathrm{Rubisco}}$ was assumed to be $30 \mu \mathrm{mol} \mathrm{L}{ }^{-1}$ (Badger et al. 1998).
Cellular leakage differed between species, being highest in E. huxleyi (0.33-0.64) and lowest in S. costatum (0.15-0.38). All species showed an increase in leakage with decreasing $\mathrm{pCO}_{2}$ in the incubation (Fig. 6b). The effect of daylength on leakage was comparatively small and differed between species (Fig. 6a). Although leakage decreased with decreasing daylength in E. huxleyi, no such effect was observed for $S$. costatum and P. globosa.

\section{Discussion}

Questions concerning aspects of carbon acquisition in marine phytoplankton have gained increasing attention over the last decade. Various studies have confirmed the operation of a CCM as well as species-specific differences in its efficiency (e.g., Burkhardt et al. 2001; Rost et al. 2003; Giordano et al. 2005). To assess the role of carbon acquisition in phytoplankton ecology factors influencing the CCM, efficiency must be understood. Ecological interpretations so far have

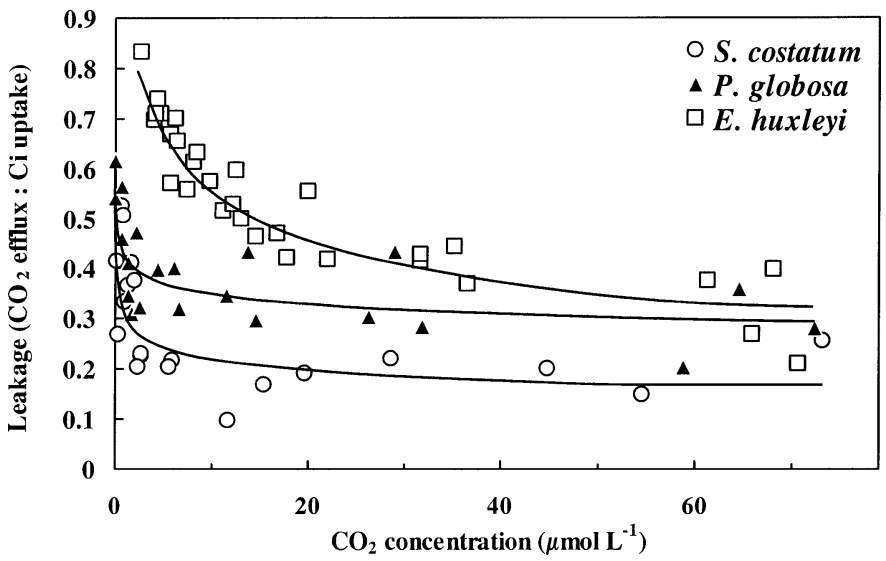

Fig. 5. Leakage $\left(\mathrm{CO}_{2}\right.$ efflux : gross $\mathrm{Ci}$ uptake) as a function of $\mathrm{CO}_{2}$ concentration in the assay for $S$. costatum, P. globosa, and E. huxleyi, obtained from cells acclimated to $360 \mathrm{ppmv}$ and continuous light. 

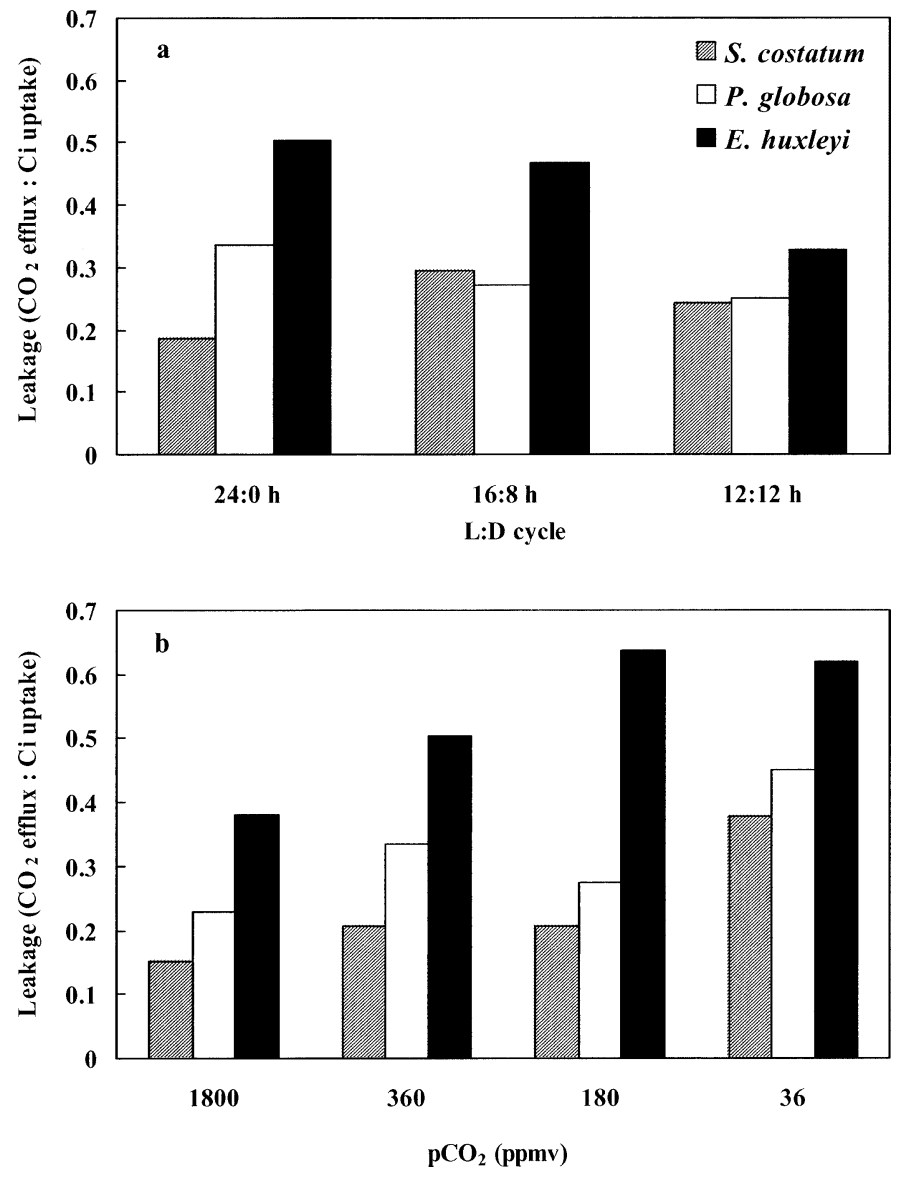

Fig. 6. Leakage $\left(\mathrm{CO}_{2}\right.$ efflux : gross $\mathrm{Ci}$ uptake) under respective culture conditions for $S$. costatum, $P$. globosa, and E. huxleyi, acclimated (a) to different $\mathrm{LD}$ cycles and (b) $\mathrm{pCO}_{2}$. The values for $\mathrm{pCO}_{2}$ treatments were calculated from previously published data (Rost et al. 2003).

focused on the influence of changing $\mathrm{Ci}$ supply. The apparent effect of photoperiod on carbon acquisition shown here indicates that other factors might be equally important for the regulation of CCM efficiency. This study also considers the effect of leakage on CCM efficiency and species-specific differences therein.

Leakage-The efficiency of a CCM in microalgae depends on the kinetics of the carbon uptake systems but also on the loss of carbon via $\mathrm{CO}_{2}$ efflux. All three species investigated here showed an increase in leakage with decreasing $\mathrm{pCO}_{2}$ in the incubation, whereas the effect of daylength was less pronounced (Figs. 5, 6). We assume $\mathrm{CO}_{2}$ to be the only or at least predominant form of inorganic carbon, which diffuses through lipid cell membranes. According to Fick's law, the $\mathrm{CO}_{2}$ flux via a membrane is a function of the $\mathrm{CO}_{2}$ concentration gradient and a permeability coefficient. Leakage therefore strongly depends on these factors, both of which differ between species and growth conditions. In case of purely diffusive $\mathrm{CO}_{2}$ uptake by microalgae, the gradient of $\mathrm{CO}_{2}$ concentration would always be inward (intracellular $\left[\mathrm{CO}_{2}\right] \leq$ ambient $\left.\left[\mathrm{CO}_{2}\right]\right)$. Only a proportion of the incoming $\mathrm{CO}_{2}$ is fixed by RubisCO, the rest leaks out of the cell. In algae with diffusive $\mathrm{CO}_{2}$ uptake, leakage tends to increase with ambient $\left[\mathrm{CO}_{2}\right]$, a relationship that is implicit in many models for ${ }^{13} \mathrm{C}$ fractionation (e.g., Rau et al. 1996). According to our results, however, leakage is highest under low ambient $\left[\mathrm{CO}_{2}\right]$. This is consistent with results of Badger et al. (1994), who observed leakage as high as 0.5 in Chlamydomonas at low $\left[\mathrm{CO}_{2}\right]$, which reduces to $<0.1$ under saturating $\left[\mathrm{CO}_{2}\right]$ levels. For microalgae operating a CCM, leakage should be a function of internal $\mathrm{CO}_{2}$ accumulation (intracellular $\left[\mathrm{CO}_{2}\right] \geq$ ambient $\left[\mathrm{CO}_{2}\right]$ ). Because active $\mathrm{Ci}$ uptake creates the highest $\mathrm{CO}_{2}$ gradient under low ambient $\left[\mathrm{CO}_{2}\right]$, the observed relationship between leakage and ambient $\left[\mathrm{CO}_{2}\right]$ should largely reflect the characteristics of the CCM employed.

Species-specific differences in leakage could also be caused by the diffusive properties of their membranes. Highly permeable membranes facilitate inward diffusion of $\mathrm{CO}_{2}$, but in the case of active $\mathrm{Ci}$ uptake, they also increase the loss of $\mathrm{CO}_{2}$. Consequently, one could expect that in species with high CCM activity, membrane permeability is generally minimized. In fact, we find the lowest leakage in $S$. costatum, which had the highest $K_{\mathrm{M}}: K_{1 / 2}$ ratios, and the highest leakage in E. huxleyi with $K_{\mathrm{M}}: K_{1 / 2}$ ratios close to 1 . It has been suggested that leakage increases the costs or decreases the efficiency of a CCM (Raven and Lucas 1985). Thus, the low efficiency in photosynthesis of E. huxleyi could partly be caused by the up to two-thirds of the gross $\mathrm{Ci}$ uptake that is subsequently lost by $\mathrm{CO}_{2}$ efflux (Fig. 6). On the other hand, leakage as part of $\mathrm{Ci}$ cycling might help to dissipate excess energy (Tchernov et al. 1997), which could explain the tolerance of $E$. huxleyi to high irradiances.

It should be noted here that estimating leakage from the initial $\mathrm{CO}_{2}$ increase on darkening has various limitations (Badger et al. 1994). The calculation is based on the assumption that the rate of diffusive $\mathrm{Ci}$ efflux in light is well represented by the rate of $\mathrm{CO}_{2}$ efflux during the first seconds of the subsequent dark phase. This approach might, however, underestimate the real $\mathrm{Ci}$ efflux because of refixation of $\mathrm{CO}_{2}$ by internal ribulose-bisphosphate in the dark and a slow response time of the inlet system of the mass spectrometer. Furthermore, energy-driven transport of $\mathrm{CO}_{2}$ as well as $\mathrm{HCO}_{3}^{-}$out of the cell might occur in light. These limitations are particularly important to consider when investigating microalgae because of their relatively small internal $\mathrm{Ci}$ pools and, hence, rates of efflux. Future investigations should pay more attention to the phenomenon of leakage and explore the mechanisms behind reduced leakage.

$\mathrm{O}_{2}$ evolution and carbon uptake kinetics - In all three species, maximum rates of photosynthesis more or less doubled under LD cycles compared with continuous light (Figs. 13 ; Table 1). Similar responses in photosynthesis were previously obtained for S. costatum (Burkhardt et al. 1999) and E. huxleyi (Nielsen 1997; Rost et al. 2002). The strong effect of photoperiod on photosynthesis was accompanied by respective changes in the carbon uptake systems. As in this study, rates of photosynthesis and carbon uptake are commonly expressed on a $\mathrm{Chl} a$ basis. In investigating the effect of daylength, however, one must consider that the Chl $a$ quota in microalgae is affected by the photoperiod and gen- 
erally increases with decreasing daylength. In $S$. costatum and E. huxleyi, the Chl $a: \mathrm{C}$ ratio was found to increase under LD cycles by approximately $20 \%$ and $15 \%$, respectively (Gilstadt et al. 1993; Nielsen 1997). Thus, the effect of photoperiod on photosynthesis and carbon uptake rates is even larger if rates are normalized to cellular carbon.

In $S$. costatum and E. huxleyi, a remarkably higher contribution of $\mathrm{HCO}_{3}^{-}$to the overall carbon uptake was observed under LD cycles, an effect also caused by decreasing $\mathrm{CO}_{2}$ supply (Rost et al. 2003). On the contrary, $P$. globosa does not seem to regulate its $\mathrm{CO}_{2}$ : $\mathrm{HCO}_{3}^{-}$uptake ratio as strongly in response to daylength. These results confirm species-specific differences in CCM regulation observed in the investigated species (Rost et al. 2003). In addition to the changes in $\mathrm{CO}_{2}: \mathrm{HCO}_{3}^{-}$use, daylength also influences affinity for inorganic carbon. Surprisingly, only E. huxleyi decreased its $K_{1 / 2}$ values for $\mathrm{O}_{2}$ evolution, whereas in $S$. costatum and $P$. globosa, a shorter photoperiod yielded generally higher $K_{1 / 2}$ values. This opposing regulation could be related to the efficiency of the employed CCM. For S. costatum and P. globosa with their efficient CCMs, an increase in affinities would not further increase the actual rate of carbon fixation because photosynthesis is already $\mathrm{CO}_{2}$ saturated under culture conditions. In view of the low affinities of E. huxleyi, however, a decrease in the $K_{1 / 2}$ value consequently leads to higher carbon fixation. In this respect, it seems puzzling that E. huxleyi does not push its affinity for carbon to the upper limit under continuous light. This could be because, under continuous light, despite lower affinities for carbon and thus lower instantaneous rates of carbon fixation, $E$. huxleyi yields equally high growth rates (Rost et al. 2002).

Disequilibrium techniques that distinguish between $\mathrm{CO}_{2}$ and $\mathrm{HCO}_{3}^{-}$as the carbon source require a lack of extracellular CA (eCA) activity. In our experiments, this was ensured by the presence of DBS, an inhibitor of eCA activity. It is a common notion that eCA increases the $\mathrm{CO}_{2}$ concentration at the plasma membrane and therefore favors $\mathrm{CO}_{2}$ uptake. For species like S. costatum or P. globosa, which possess eCA activities under various conditions (Rost et al. 2003), the contribution of $\mathrm{CO}_{2}$ to photosynthesis would then probably be higher in the "real world" than was obtained in our assays. In E. huxleyi, however, only very low eCA activities were observed under various conditions (Rost et al. 2003), and the presence of DBS would therefore have not significantly affected estimates of the $\mathrm{CO}_{2}$ contribution.

Effects of the photoperiod on photosynthetic activity have previously been investigated in phytoplankton. In the marine diatom Thalassiosira fluviatilis, Hobson et al. (1985) observed that RubisCO content did not vary significantly; nevertheless, both light-saturated and light-limited rates of total Ci uptake increased with decreasing photoperiod. In S. costatum, Mortain-Bertrand et al. (1987b) found increasing RubisCO carboxylase activities as the photoperiod changed from continuous light to a $12: 12$ and then a 2:2 LD cycle. Both data sets support the conclusion that cells adapt to short photoperiods by increasing in vivo RubisCO carboxylase activity without increasing their cellular enzyme concentration. One way to achieve this would be up-regulation of the classical CCM. In this regard, it was also suggested that a $\mathrm{C}_{4^{-}}$ like pathway plays an increasing role in overall carbon ac- quisition under short photoperiods (Mortrain-Bertrain et al. 1987a).

The above-mentioned effects of the photoperiod on phytoplankton bear an interesting resemblance to macroalgae growing in different areas of the tidal zone. Because of the tidal cycle, intertidal species are restricted in the length of time they can photosynthesize. To overcome this shortcoming they seem to have developed a very efficient CCM on the basis of $\mathrm{HCO}_{3}^{-}$use, with high affinities for $\mathrm{CO}_{2}$ and $\mathrm{HCO}_{3}^{-}$, whereas subtidal species have low affinities and tend to rely on $\mathrm{CO}_{2}$ (Johnston et al. 1992).

CCM regulation as a function of $\mathrm{Ci}$ demand-Microalgae were found to up-regulate their CCMs when ambient $\mathrm{CO}_{2}$ concentrations decrease, presumably to prevent " $\mathrm{CO}_{2}$ shortage" at the site of carboxylation. It has been suggested that arising $\mathrm{CO}_{2}$ shortage is sensed directly at the plasmalemma (Masuda et al. 1998), by changes in the redox state of the photosynthetic electron transport carriers or in the level of photorespiratory metabolites (Kaplan et al. 2001). Regardless of the actual signal transduction pathway, $\mathrm{CO}_{2}$ shortage is not only a function of the $\mathrm{Ci}$ supply but also of the $\mathrm{Ci}$ demand of the cell. While the $\mathrm{CO}_{2}$ supply is proportional to ambient $\mathrm{CO}_{2}$ concentration, the $\mathrm{Ci}$ demand of a cell is reflected in its carbon-specific growth rate.

PFD largely controls the carbon-specific growth rate of microalgae, especially under nutrient-replete conditions. Below light saturation, increasing PFD enhances the $\mathrm{Ci}$ demand and thus the need for higher CCM activity. Beardall (1991) observed increasing $\mathrm{Ci}$ affinities in $\mathrm{O}_{2}$ evolution with increasing PFD-dependent growth rates for the cyanobacteria Anabaena variabilis. Increased CCM efficiency at higher PFD was also found for the green alga Chlorella vulgaris (Shiraiwa and Miyachi 1983), the dinoflagellate Peridinium gatunense (Berman-Frank et al. 1998), and the rhodophytes Palmaria palmata and Laurencia pinnatifida (Kübler and Raven 1994). Some genes in the cyanobacteria Synechocystis that respond to low $\mathrm{CO}_{2}$ conditions were also up-regulated under high light (Hihara et al. 2001; McGinn et al. 2003). Most phytoplankton species reach photosynthetic carbon saturation under ambient $\mathrm{Ci}$ conditions, even at high PFDs. E. huxleyi, with its rather inefficient CCM, is only able to do so under low PFDs. Under high PFDs, E. huxleyi

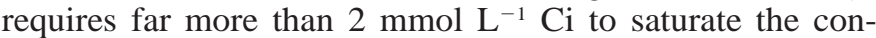
sequently higher $\mathrm{Ci}$ demand in photosynthesis (Nimer and Merrett 1993).

The observed relationship between PFD and CCM capacity has been ascribed to changes in the degree of energy limitation (see Giordano et al. 2005). Yet, this response to PFD is also consistent with a regulation of CCM efficiency as a function of the $\mathrm{Ci}$ demand of the cell. Because photosynthesis cannot go faster than either the carboxylase activity or the electron transport rate (Farquar et al. 1980), the adjustment of both processes is critical for optimal performance, suggesting that both explanations do not preclude each other. In fact, by reacting to the redox state of its photosynthetic electron transport, the cell would respond equally to limitations on "both ends" of photosynthesis.

Duration of the photoperiod can also influence the carbonspecific growth rate of phytoplankton because some species 
apparently compensate for a shorter photoperiod by increasing the rate of carbon fixation during the light period. According to our data, this increase in "instantaneous $\mathrm{Ci}$ demand" under LD cycles is accompanied by an up-regulation in $\mathrm{Ci}$ uptake. Because the observed higher rates of photosynthesis and $\mathrm{Ci}$ uptake were accomplished under shorter daylength, and thus lower absolute daily energy supply, we argue that under these conditions, the $\mathrm{Ci}$ demand, and not energy supply, is the trigger for CCM regulation.

If the duration of the photoperiod affects the $\mathrm{Ci}$ demand of microalgae, it might be crucial at what time scales the $\mathrm{CCM}$ can be up- and down-regulated. Likewise, fast changes in the Ci demand, as might be imposed by varying PFDs, also require fast regulation in the CCMs of microalgae. In fact, the incident PFD under which the uptake rates were measured had a stronger control on CCM efficiency than the PFD did in acclimation (Beardall 1991). In C. reinhardtii, high-affinity $\mathrm{Ci}$ uptake systems were completely induced within $<20$ min (G. Amoroso, pers. comm.). Nimer et al. (1998) showed that extracellular CA activity in S. costatum reached maximum values 30 min after being transferred into high-pH media from the dark.

PFD and duration of the photoperiod were found to affect photosynthesis and CCM regulation of phytoplankton, presumably by altering the $\mathrm{Ci}$ demand of the cell. If this factor turns out to have a significant influence on the regulation of the CCM, species-specific differences in carbon acquisition could play a significant role in phytoplankton ecology.

Ecological implications-To assess the role of carbon acquisition in phytoplankton ecology, the controlling factors in the natural environment must be identified. Owing to the low affinity of RubisCO with $K_{\mathrm{M}}\left(\mathrm{CO}_{2}\right)$ of $20-70 \mu \mathrm{mol} \mathrm{L}^{-1}$ and ambient oceanic $\mathrm{CO}_{2}$ concentrations of $\sim 5-20 \mu \mathrm{mol} \mathrm{L}-1$, diffusive $\mathrm{CO}_{2}$ supply is insufficient to saturate photosynthetic carbon fixation. Hence, the low $\mathrm{CO}_{2}$ supply could be seen as a raison d'être for the CCM, making it essential for most microalgae under conditions in the ocean. As argued here, the degree of CCM regulation should be directly proportional to the $\mathrm{CO}_{2}$ shortage at RubisCO, which in turn is influenced by $\mathrm{CO}_{2}$ supply and $\mathrm{Ci}$ demand of the cell.

Only a few studies have addressed the regulation of carbon acquisition over the natural range in $\mathrm{CO}_{2}$ concentrations. With decreasing $\mathrm{CO}_{2}$ concentrations, as occurs during the development of a phytoplankton bloom, CCM activity concomitantly increases for most species (e.g., Berman-Frank et al. 1998; Elzenga et al. 2000; Rost et al. 2003). Yet, the variation in the $\mathrm{CO}_{2}$ supply is rather small in the open ocean compared with the range in carbon-specific growth rates, which can differ by $>10$-fold. Considering the instantaneous rates imposed by changes in the photoperiod length as well as PFDs, the variation in $\mathrm{Ci}$ demand would be even larger. Light conditions for phytoplankton are highly variable in aquatic environments, most importantly because of their vertical motion in the water column. For a vertical displacement on the order of $10 \mathrm{~m}$, time scales of cycling have been found to vary from about half an hour to hundreds of hours, depending on wind speed, current shear, and stratification (Denman and Gargett 1983). We therefore suggest that the
$\mathrm{CCM}$ in the natural environment is regulated by the $\mathrm{Ci}$ demand rather than the $\mathrm{CO}_{2}$ supply.

Light conditions, and thus the cellular $\mathrm{Ci}$ demand, might differ between ecological niches. Diatoms usually dominate under early spring conditions (i.e., in turbulent waters with initially high nutrient concentrations). In turbulent environments, light conditions vary with a high frequency and high amplitude; thus, depending on the mixing depth, cells can thrive under subsaturating light intensities most of the time, whereas at the surface, irradiances are very high. Under these conditions, it is critical to closely adjust $\mathrm{Ci}$ uptake to the changing $\mathrm{Ci}$ demand because this regulation in the CCM is essential for an overall efficient light use. Under subsaturating irradiances, the CCM can be down-regulated, whereas under saturating irradiance, the reactions of the Calvin-Benson cycle have to be maximized to ensure high rates of carbon fixation. $\mathrm{A} \mathrm{C}_{4}$-like pathway, as it might operate in diatoms, could furthermore supplement the classical CCM under highly fluctuating light environments in a way that allows temporal "storage of $\mathrm{CO}_{2}$ " at low irradiance and " $\mathrm{CO}_{2}$ release" at times of increased photosynthetic $\mathrm{Ci}$ demand during high illumination close to the surface (Riebesell 2000).

According to our results, diatoms should be most efficient in coping with early spring conditions. In fact, we suggest that a highly efficient and regulated CCM is a prerequisite for phytoplankton to dominate early spring blooms. Langdon (1988) concluded in a literature review that diatoms were best adapted for growth under low irradiance and attributed this result to the high $\mathrm{Chl} a: \mathrm{C}$ ratios and low maintenance respiration rates of diatoms. Tortell (2000) suggested that the high specificity of diatom RubisCO and low $\mathrm{Ci}$ accumulation might contribute to their ability to grow well under low light. Both explanations, however, do not consider the high variability in irradiance under early spring conditions that requires flexibility in photosynthesis. The ability of diatoms to regulate their CCM could partly determine their competitiveness over Phaeocystis, which usually form blooms after diatoms have exhausted silicate concentrations. E. huxleyi develops blooms in temperate and subpolar regions during the summer months when the water column becomes stratified and nutrient concentrations are low. In stratified environments, light conditions are less variable (i.e., the cells grow under generally high and rather constant irradiances). On the basis of our results, E. huxleyi might prefer such stable environments in which the $\mathrm{Ci}$ demand is moderate, and thus it does not depend on high instantaneous rates of carbon fixation for its ecological success. Consequently, we argue that owing to its inefficient CCM, E. huxleyi cannot compete with diatoms under early spring condition.

Until recently, the potential role of carbon acquisition in marine phytoplankton ecology has largely been ignored. Many studies have meanwhile confirmed the operation of a $\mathrm{CCM}$ in various phytoplankton species. Ecological interpretations so far have focused on the effect of changes in $\mathrm{Ci}$ supply. A consideration of $\mathrm{Ci}$ demand provides a novel view on the role of carbon acquisition in phytoplankton ecology. The above-suggested influence on phytoplankton succession, however, remains to be tested. 


\section{References}

Badger, M. R., T. J. Andrews, S. M. Whitney, M. Ludwig, D. C. Yellowlees, W. Leggat, and G. D. Price. 1998. The diversity and coevolution of Rubisco, plastids, pyrenoids, and chloroplast-based $\mathrm{CO}_{2}$-concentrating mechanisms in algae. Can. J. Bot. 76: 1052-1071.

- K. PalmQVist, And J.-W. YU. 1994. Measurement of $\mathrm{CO}_{2}$ and $\mathrm{HCO}_{3}^{-}$fluxes in cyanobacteria and microalgae during steady-state photosynthesis. Physiol. Plant. 90: 529-536.

Beardall, J. 1991. Effects of photon flux density on the ' $\mathrm{CO}_{2}$ concentrating mechanism' of the cyanobacterium Anabaena variabilis. J. Plankton Res. 13: 133-141.

Berman-Frank, I., J. Erez, and A. Kaplan. 1998. Growth of dinoflagellates as influenced by the availability of $\mathrm{CO}_{2}$ and inorganic carbon uptake in a lake ecosystem. Can. J. Bot. 76: 1043-1051.

Burkhardt, S., G. Amoroso, U. Riebesell, AND D. SÜltemeyer. 2001. $\mathrm{CO}_{2}$ and $\mathrm{HCO}_{3}^{-}$uptake in marine diatoms acclimated to different $\mathrm{CO}_{2}$ concentrations. Limnol. Oceanogr. 46: 13781391.

—, U. Riebesell, AND I. Zondervan. 1999. Stable carbon isotope fractionation by marine phytoplankton in response to daylength, growth rate, and $\mathrm{CO}_{2}$ availability. Mar. Ecol. Prog. Ser. 184: 31-41.

Denman, K. L., And A. E. Gargett. 1983. Time and space scales of vertical mixing and advection of phytoplankton in the upper ocean. Limnol. Oceanogr. 28: 801-815.

Elzenga, J. T. M., H. B. A. Prins, And J. Stefels. 2000. The role of extracellular carbonic anhydrase activity in inorganic carbon utilization of Phaeocystis globosa (Prymnesiophyceae): A comparison with other marine algae using the isotope disequilibrium technique. Limnol. Oceanogr. 45: 372-380.

Farquar, G. D., S. von Caemmerer, and J. A. Berry. 1980. A biochemical model of photosynthetic $\mathrm{CO}_{2}$ assimilation in leaves of C3 species. Planta 149: 78-90.

Gilstadt, M., G. Johnson, and E. Sakshaug. 1993. Photosynthetic parameters, pigment composition and respiration rates of the marine diatom Skeletonema costatum grown in continuous light and a 12:12 h light-dark cycle. J. Plankton Res. 15: 939951.

Giordano, M. J. Beardall, AND J. A. Raven. 2005. $\mathrm{CO}_{2}$ concentrating mechanisms in algae: Mechanisms, environmental modulation, and evolution. Annu. Rev. Plant Biol. 56: 99-131.

Guillard, R. R. L., AND J. H. Ryther. 1962. Studies of marine planktonic diatoms. Can. J. Microbiol. 8: 229-239.

Hihara, Y., A. Kamei, M. Kanehisa, A. Kaplan, AND M. IKeUChi. 2001. DNA microarray analysis of cyanobacterial gene expression during acclimation to high light. Plant Cell 13: 793806.

Hobson, L. A., W. J. Morris, And K. P. Guest. 1985. Varying photoperiod, ribulose 1,5-bisphosphate carboxylase/oxygenase and $\mathrm{CO}_{2}$ uptake in Thalassiosira fluviatilis (Bacillariophyceae). Plant Physiol. 79: 833-837.

Johnston, A. M., S. C. Maberly, and J. A. Raven. 1992. The acquisition of inorganic carbon by four red macroalgae. Oecologia 92: 317-326.

Kaplan, A., Y. Helman, D. Tchernov, and L. Reinhold. 2001. Acclimation of photosynthetic microorganisms to changing ambient $\mathrm{CO}_{2}$ concentration. Proc. Natl. Acad. Sci. USA 98: 4817-4818.

KüBler, J. E., AND J. A. Raven. 1994. Consequences of light limitation for carbon acquisition in three rhodophytes. Mar. Ecol. Prog. Ser. 110: 203-209.
LANGDON, C. 1988. On the causes of interspecific differences in the growth-irradiance relationship for phytoplankton II. A general review. J. Plankton Res. 10: 1991-1312.

Marcus, Y., G. Schuster, A. Michaels, and A. Kaplan. 1986. Adaptation to $\mathrm{CO}_{2}$ level and changes in the phosphorylation of thylakoid proteins during the cell cycle of Chlamydomonas reinhardtii. Plant Physiol. 80: 604-607.

Masuda, Y., G. G. Bozzo, and B. Colman. 1998. Regulation of dissolved inorganic carbon transport in green algae. Can. J. Bot. 76: 1072-1083.

McGinn, J. P., G. D. Price, R. Maleszka, and M. R. Badger. 2003. Inorganic carbon limitation and light control the expression of transcripts related to the $\mathrm{CO}_{2}$-concentrating mechanisms in the cyanobacterium Synechocystis sp. strain PCC6803. Plant Physiol. 132: 218-229.

Mortain-Bertrand, A., C. Descolas-Gros, and H. Jupin. 1987a. Stimulating effect of light-to-dark transitions on carbon assimilation by a marine diatom. J. Exp. Mar. Biol. Ecol. 112: $11-26$.

1987b. Short-term ${ }^{14} \mathrm{C}$ incorporation in Skeletonema costatum (Greville) Cleve (Bacillariophyceae) as a function of light regime. Phycologia 26: 262-269.

NiELSEN, M. V. 1997. Growth, dark respiration and photosynthetic parameters of the coccolithophorid Emiliania huxleyi (Prymnesiophyceae) acclimated to different daylength-irradiance combinations. J. Phycol. 33: 818-822.

Nimer, N. A., AND M. J. Merrett. 1993. Calcification rate in Emiliania huxleyi Lohmann in response to light, nitrate and availability of inorganic carbon. New Phytol. 123: 673-677.

, M. WARren, AND M. J. MerretT. 1998. The regulation of photosynthetic rate and activation of extracellular carbonic anhydrase under $\mathrm{CO}_{2}$-limiting conditions in the marine diatom Skeletonema costatum. Plant Cell Environ. 21: 805-812.

PAlmQvist, K., J.-W. YU, AND M. R. BAdGeR. 1994. Carbonic anhydrase activity and inorganic carbon fluxes in low- and high$\mathrm{C}_{\mathrm{i}}$ cells of Chlamydomonas reinhardtii and Scenedesmus obliquus. Physiol. Plant. 90: 537-547.

Price, L. L., YiN K., AND P. J. HARRISON. 1998. Influence of continuous light and L:D cycles on the growth and chemical composition of Prymnesiophyceae including coccolithophores. J. Exp. Mar. Biol. Ecol. 223: 223-234.

Rau, G. H., U. Riebesell, and D. Wolf-Gladrow. 1996. A model of photosynthetic ${ }^{13} \mathrm{C}$ fractionation by marine phytoplankton based on diffusive molecular $\mathrm{CO}_{2}$ uptake. Mar. Ecol. Prog. Ser. 133: $275-285$.

RAVEN, J. A., AND W. J. LuCAS. 1985. Energy costs of carbon acquisition, p. 305-324. In W. J. Lucas and J. A. Berry [eds.], Inorganic carbon uptake by aquatic photosynthetic organism. The American Society of Plant Physiologists.

Reinfelder, J. R., A. M. L. Kraepiel, and F. M. M. Morel. 2000. Unicellular C4 photosynthesis in a marine diatom. Nature 407: 996-999.

- A. J. Milligan, And F. M. M. Morel. 2004. The role of the $\mathrm{C}_{4}$ pathway in carbon accumulation and fixation in a marine diatom. Plant Physiol. 135: 2106-2111.

Riebesell, U. 2000. Carbon fix for a diatom. Nature 407: 959960.

Rost, B., U. Riebesell, S. Burkhardt, and D. SÜltemeyer. 2003. Carbon acquisition of bloom-forming marine phytoplankton. Limnol. Oceanogr. 48: 55-67.

- I. ZONDERVAN, AND U. RIEBESELL. 2002. Light-dependent carbon isotope fractionation in the coccolithophorid Emiliania huxleyi. Limnol. Oceanogr. 47: 120-128.

SHIRAIWA, Y., AND S. MIYACHI. 1983. Factors controlling induction 
of carbonic anhydrase and efficiency of photosynthesis in Chlorella vulgaris 11h cells. Plant Cell Physiol. 26: 919-923.

Sültemeyer, D., B. Klughammer, M. R. Badger, And G. D. PRICE. 1998. Fast induction of high-affinity $\mathrm{HCO}_{3}^{-}$transport in cyanobacteria. Plant Physiol. 116: 183-192.

Tchernov, D., M. Hassidim, B. Luz, A. Sukenik, L. Reinhold, AND A. KAPLAN. 1997. Sustained net $\mathrm{CO}_{2}$ evolution during photosynthesis by marine microorganisms. Curr. Biol. 7: 723-728.
TORTELl, P. D. 2000. Evolutionary and ecological perspectives on carbon acquisition in phytoplankton. Limnol. Oceanogr. 45: 744-750.

Received: 18 January 2005 Accepted: 2 August 2005

Amended: 16 August 2005 